\title{
Erratum to: Impacts of climatic disasters in coastal Bangladesh: why does private adaptive capacity differ?
}

\author{
M. Mustafa Saroar · Jayant K. Routray
}

Published online: 26 August 2011

(C) Springer-Verlag 2011

\section{Erratum to: Reg Environ Change \\ DOI 10.1007/s10113-011-0247-4}

In original publication of this article, the tables were cited incorrectly in the footnote of Table 5. The correct footnote is given below:

* Significant at 0.05 level; ** significant at 0.01 level; *** significant at Bonferroni corrected 0.001 level

${ }^{a}$ Elaborated form of the factors/variables that are shown in Table 1

${ }^{\mathrm{b}}$ Mean difference in adaptive capacity between reference group (I) and comparison group (s) (Ji); Ji $=\mathrm{J} 1$, J2, $\mathrm{J} 3, \ldots . . \mathrm{Jn}$. Reference group is always indicated by (I)

${ }^{\mathrm{c}}$ Indicates computation of mean difference in adaptive capacity between reference group (I) and comparison group(s) is not necessary since in earlier Table 4 it is shown that the influence of that particular factor on that particular dimension of adaptive capacity is not significant even at 0.05 level. For illustrative purpose let us consider factor/variable "age". Table 4 reports that only adaptive capacity against "loss of employment in offshore activities" and "crisis of potable water and public health risk" are significantly influenced by "age". That means respondent's "age" does not have any significant influence on other 3 major dimensions of impacts of SLR on livelihood (see Table 4). Therefore, in Table 5 mean difference in adaptive capacity (against that 3 major categories) among various age groups are not computed (marked as "n/a")

The online version of the original article can be found under doi:10.1007/s10113-011-0247-4.

M. M. Saroar $(\bowtie)$. J. K. Routray

School of Environment, Resources and Development (SERD),

Asian Institute of Technology (AIT), P. O. Box 4,

Klong Luang, Pathum Thani, Bangkok 12120, Thailand

e-mail: st105227@ait.ac.th; saroar.mustafa@yahoo.com

M. M. Saroar

Urban and Rural Planning Discipline, School of Science

Engineering and Technology (SET), Khulna University,

Khulna 9208, Bangladesh 